\title{
Cognitive Impairments in Early Parkinson's Disease Are Accompanied by Reductions in Activity in Frontostriatal Neural Circuitry
}

\author{
Simon J. G. Lewis, ${ }^{1,2}$ Anja Dove, ${ }^{4}$ Trevor W. Robbins, ${ }^{3}$ Roger A. Barker, ${ }^{1,2 *}$ and Adrian M. Owen ${ }^{4 *}$ \\ ${ }^{1}$ Cambridge Centre for Brain Repair and Departments of ${ }^{2}$ Neurology and ${ }^{3}$ Experimental Psychology, University of Cambridge, and ${ }^{4}$ Medical Research \\ Council Cognition and Brain Sciences Unit, Cambridge, United Kingdom CB2 2EF
}

\begin{abstract}
Studies in patients with Parkinson's disease (PD) suggest that the characteristic motor symptoms of the disorder are frequently accompanied by impairments in cognition that are most profound in tasks of executive function. Neuropsychological deficits are not an inevitable consequence of the disease, yet the reasons underlying cognitive heterogeneity in PD are not well understood. To determine the underlying neural correlate of these cognitive deficits, we used event-related functional magnetic resonance imaging (fMRI) to compare groups of cognitively impaired and unimpaired patients, matched on all other clinical measures. fMRI revealed significant signal intensity reductions during a working-memory paradigm in specific striatal and frontal lobe sites in patients with cognitive impairment compared with those patients who were not cognitively unimpaired. These results demonstrate that cognitive deficits in PD are accompanied by neural changes that are related to, but distinct from, those changes that underlie motoric deficits in these patients. Furthermore, they suggest that fMRI may provide a valuable tool for identifying patients who may benefit from targeted therapeutic strategies.
\end{abstract}

Key words: Parkinson's disease; working memory; functional MRI; heterogeneity; frontal lobes; basal ganglia

\section{Introduction}

Studies of patients with Parkinson's disease (PD) suggest that the characteristic clinical symptoms of bradykinesia, rigidity, and resting tremor are frequently accompanied by impairments in cognitive function. Between 15 and $20 \%$ of PD patients develop a frank dementia (Brown and Marsden, 1984), and less severe cognitive impairment is a well recognized feature of the disease that has been shown to be an important predictor for quality of life (Karlsen et al., 1998; Schrag et al., 2000). The pattern of cognitive impairments seen in the early stages of PD resembles that produced by frontal-lobe damage and includes deficits of executive functions, such as planning and working memory (Lees and Smith, 1983; Taylor et al., 1986). This executive dysfunction in PD has been shown previously to be extremely sensitive to the effects of controlled L-dopa withdrawal (Lange et al., 1992), suggesting a predominantly dopaminergic substrate for the deficits observed.

Dopaminergic neuronal loss represents the primary neuropathology in PD and occurs predominantly in the nigrostriatal tract

\footnotetext{
Received Jan. 21, 2003; revised April 29, 2003; accepted May 16, 2003.

This study was conducted as part of a Medical Research Council cooperative group grant, The Origins of Parkinson's Disease and Its Heterogeneity (G0001067), and in collaboration with the Medical Research Council Behavioural and Clinical Neuroscience Centre. This work was assisted by a Parkinson's Disease Society project grant and the British Medical Association's Vera Down Award. We thank the efforts of Drs. Matthew Brett and Rhodri Cusack of the Medical Research Council Cognition and Brain Sciences Unit along with Dr. Adrian Carpenter and his dedicated staff at the Wolfson Brain Imaging (entre (Cambridge, UK).

*R.A.B. and A.M.O. are joint senior authors.

Correspondence should be addressed to Dr. Simon J. G. Lewis, Cambridge Centre for Brain Repair, Forvie Site, Addenbrooke's Hospital, Cambridge, CB2 2PY, UK. E-mail: sjgl2@wbic.cam.ac.uk.

Copyright $\odot 2003$ Society for Neuroscience $\quad 0270-6474 / 03 / 236351-06 \$ 15.00 / 0$
}

and, to a lesser extent, in the mesocortical pathway in which neurons project predominantly from the ventral tegmental area and the medial substantia nigra pars compacta to the neocortex (Jellinger, 2001). Previous functional neuroimaging studies exploring the executive deficits in PD have provided supporting evidence for a role of both disruption in the nigrostriatal (Owen et al., 1998a; Dagher et al., 2001) and mesocortical (Cools et al., 2002; Mattay et al., 2002) pathways. Although not mutually exclusive, the potentially conflicting results of these cognitive neuroimaging studies in PD may reflect the heterogeneity observed within the patient population. For example, across studies, patient groups typically vary over multiple dimensions including disease severity (Owen et al., 1992, 1993), medication (Lange et al., 1992; Owen et al., 1992), age (Aarsland et al., 1996), dominant motor symptom (Zetusky et al., 1985; Jankovic et al., 1990), and age of onset (Gibb and Lees, 1988b; Jankovic et al., 1990), rendering comparisons between studies rather difficult. However, it has been demonstrated recently that two subgroups of PD patients who were well matched on all of these demographic factors can still differ in terms of executive function (Lewis et al., 2003).

In this study, the neural basis for cognitive heterogeneity in PD was explored using event-related functional magnetic resonance brain imaging (fMRI). Patients in the earlier stages of the disease who were well matched on a range of clinical and neuropsychological measures, but differed on their performance of a standard clinical executive task, underwent event-related fMRI on a novel working-memory task along with a control group of healthy, age-matched volunteers. It was hypothesized that cognitive dysfunction in the executively impaired subgroup of patients 
with PD would be accompanied by underactivity in their basal ganglia and possibly in their frontal cortical targets.

\section{Materials and Methods}

Subjects. Ten healthy volunteers ( $50-70$ years of age; 5 male), 10 cognitively unimpaired patients (47-70 years of age; 6 male), and 11 patients with selective executive impairment (44-66 years of age; 7 male) performed the fMRI experiment. Patients for this study were recruited from the Cambridge Centre for Brain Repair $\mathrm{PD}$ research clinic, having satisfied diagnostic criteria (Gibb and Lees, 1988a), and subjects had given informed consent to participate. This project had been granted approval by the local regional ethics committee of Addenbrooke's National Health Service trust hospital. All of the subjects were right-handed and had British English as a first language.

Before fMRI testing, patients underwent a full clinical assessment including Hoehn and Yahr staging (Hoehn and Yahr, 1967), the unified Parkinson's disease rating scale (UPDRS) (Fahn and Elton, 1987), and a general neuropsychological test battery that included mini-mental state examination (Folstein et al., 1975), verbal (Benton, 1983) and categorical fluency (Goodglass, 1972), along with the motor screening task, pattern and spatial recognition memory, and Tower of London planning task recorded on the Cambridge Neuropsychological Test Automated Battery (Owen et al., 1992). Deriving the ratio of a tremor-nontremor score assessed motor phenotype. The tremor score was derived from the sum of items 16 and $20-26$ on the UPDRS divided by 8 (the number of items included) and represented the degree of tremor reported in the activitiesof-daily-living section of the UPDRS, along with objective tremor at rest and with action, determined on physical examination in section III of the UPDRS. The nontremor score was derived from the sum of items 5, 7, $12-15,18,19$, and $27-44$ on the UPDRS divided by 26 (the number of items included). This measure assessed speech, swallowing, ability to turn in bed, falls, freezing, and walking from the activities-of-daily-living section, as well as speech, facial expression, rigidity, bradykinesia, ability to stand, posture, gait, and postural stability, determined by the motoric examination in the UPDRS. Furthermore, no patients showed any evidence of clinical depression and were also rated on the Beck depression inventory (Beck et al., 1961). Patient subgroups were divided on the basis of their performance accuracy on the Tower of London planning task (Lewis et al., 2003), and all of the testing was performed with patients taking their regular medications.

Experimental paradigm. The Tower of London planning task has been shown to provide an excellent clinical measure in identifying executive impairment, as well as differentiating between patients with PD and other neuropathological conditions (Owen et al., 1992). However, the task is cognitively complex including aspects of working memory, problem solving, and planning. Therefore, in this study, patients and controls were evaluated on a working-memory task (Lewis et al., 2003) that was specifically designed to disentangle some of these cognitive processes. On each trial, subjects were presented with a sequence of four different consonants that had to be retained subvocally in memory in the order in which they were presented (Fig. 1). After a variable (maintenance) delay period $(9-14 \mathrm{sec})$, a cue word was presented in the center of the screen that instructed the subject on whether the letter sequence was to be recalled verbatim (retrieval-only condition) or whether the letters had to be reordered in one of two prelearned ways that required either simple or more complex manipulation of the remembered information, as well as retrieval. Specifically, simple manipulation required the subject to recall the digits in the following order: the third, fourth, first, and second digit of the original memory list, and for complex manipulation, the middle letters were reordered such that the first, then the third, then the second, and then the fourth letter of the original memory list were recalled. After the cue, a blank screen was presented until the subject indicated, by pressing a response button under the ring finger, that they had the required sequence of letters in mind. This first response triggered the appearance of two sets of four letters above and below the center of the screen. The subject was required to select the correct answer (from a similar, yet incorrect, foil) by pressing one of the two response keys under the index and middle fingers, and this period served as a motor control for the working-memory processes recorded during the first response phase. The foil was constructed such that identification of the correct answer required the subject to check through the sequences fully.

Subjects performed three blocks of 18 randomized trials of the working-memory paradigm, which gave equal weighting to retrieval, simple manipulation, and complex manipulation conditions. Behavioral accuracy and response time data were analyzed using repeated measures ANOVA or, where appropriate, one-way ANOVA using SPSS-PC software.

Data acquisition. Subjects were positioned to lie comfortably in the scanner with a forehead-restraining strip and various foam pads to ensure head fixation. The paradigm was presented on a screen positioned in front of the subjects' eyes, and a button box was placed under the right hand, connected to the stimulus computer, which allowed the accurate recording of subjects' responses via keys positioned under the first three fingers.

Functional images sensitive to blood oxygenation level-dependent (BOLD) contrasts were acquired by $\mathrm{T} 2^{\star}$-weighted echo planar MRI (repetition time, $3 \mathrm{sec}$; echo time, $27.5 \mathrm{msec}$; flip angle, $90^{\circ}$; 21 sequential slices covering the entire brain; voxel size, $3.9 \times 3.9 \times 5 \mathrm{~mm}$ ) on a 3 tesla scanner (Bruker Medspec, Ettlingen, Germany). SPM99 software was used for image processing and analysis. The first $6 \mathrm{vol}$ of images were discarded to allow for $\mathrm{T} 1$ equilibration. The remaining images were realigned to the first image, sinc-interpolated over time to correct for differences in slice-acquisition times over the volume. Phase maps acquired at the time of scanning were then used to correct for distortion to the echo planar images (EPIs) resulting from inhomogeneities in the magnetic field (Jezzard and Balaban, 1995). Phase images underwent phase unwrapping (Cusack and Papadakis, 2002) and normalization with cost function masking (Brett et al., 2001) into a standard stereotaxic space (Montreal Neurological Institute, Montreal, Canada) to allow intersubject comparison. The data were spatially smoothed with a Gaussian kernel (full width at half-maximum, $12 \mathrm{~mm}$ ).

Data analysis. Statistical parametric maps were calculated for each subject with a general linear model (Friston et al., 1995). This first-level analysis included covariates for neuronal responses elicited during stimulus presentation, maintenance period, retrieval conditions, simple and complex manipulation conditions, the motor control period, and the rest period. A variable-length boxcar function was used to model all of the events, except stimulus presentation, which had a fixed length. Each boxcar function was convolved by a canonical hemodynamic response (Friston et al., 1998). Additionally, six motion parameters derived from 
Table 1. Demographic data

\begin{tabular}{|c|c|c|c|c|}
\hline Demographic data & $\mathbf{P D}(n=10)$ & $\mathrm{PD}(n=11)$ & Controls $(n=10)$ & $p$ value \\
\hline Age (years) & $57.7 \pm 2.4$ & $60.9 \pm 2.2$ & $62.4 \pm 2.0$ & NS \\
\hline Duration of disease (years) & $4.7 \pm 1.1$ & $5.9 \pm 1.0$ & & NS \\
\hline Motor phenotype & $0.9 \pm 0.7$ & $0.8 \pm 0.8$ & & NS \\
\hline Onset side & Right, 5; left, 5 & Right, 5; left, 6 & & NS \\
\hline Hoehn \& Yahr stage & $2.0 \pm 0.0$ & $2.0 \pm 0.0$ & & NS \\
\hline UPDRS & $33.2 \pm 3.5$ & $39.2 \pm 4.3$ & & NS \\
\hline Mini-mental state examination & $29.6 \pm 0.2$ & $29.6 \pm 0.2$ & & NS \\
\hline FAS fluency & $47.1 \pm 2.7$ & $40.5 \pm 4.9$ & & NS \\
\hline Categorical fluency & $26.2 \pm 1.6$ & $21.5 \pm 1.6$ & & NS \\
\hline Motor latency (msec) & $1113.4 \pm 189.7$ & $1065.7 \pm 50.7$ & & NS \\
\hline Pattern recognition (maximum score $=24$ ) & $21.9 \pm 0.6$ & $20.1 \pm 0.7$ & & NS \\
\hline Spatial recognition (maximum score $=20$ ) & $15.4 \pm 0.8$ & $14.9 \pm 0.7$ & & NS \\
\hline Beck Depression Inventory & $5.4 \pm 1.3$ & $9.8 \pm 1.8$ & & NS \\
\hline L-dopa dose (mg) & $545.0 \pm 122.2$ & $409.1 \pm 124.5$ & & NS \\
\hline Dopamine agonist use & 7 & 8 & & NS \\
\hline Tower of London (maximum = 14) & $12.5 \pm 0.3$ & $6.8 \pm 0.6$ & & $<0.001$ \\
\hline
\end{tabular}

Demographic data (mean \pm SEM) showing no significant differences among the patient subgroups $(p>0.05)$. Performance accuracy on the Tower of London planning task was used to separate those patients with a selective executive impairment $(\mathbf{P D})$ from those with no cognitive deficit $(\square \mathrm{PD})$ before fMRI testing.

the realignment preprocessing to correct for residual movement artifacts were included in the model, and a high-pass filter with a cutoff of $300 \mathrm{sec}$ was used to correct for low-frequency drifts in BOLD signal (Holmes et al., 1997). Parameter estimates for each covariate were calculated from the least-mean-squares fit of the model to the data.

To determine the activation pattern implicit in the processes of working memory, the images of parameter estimates for the contrast combining all of the retrieval and manipulation conditions against the maintenance period for each subject were entered into a second-level random-effects analysis using a one-sample $t$ test corrected for multiple comparisons using random field theory (Worsley et al., 1996) at $p<0.05$. The activation pattern derived from this contrast was used to inform a region-of-interest (ROI) analysis to compare brain activation between the patient subgroups. Cortical ROIs were generated within SPM99 as spheres (radius, $5 \mathrm{~mm}$ ) centered on each of the coordinates of maximal cortical activation observed during the processes of working memory, while anatomically defined ROIs for the entire putamen and caudate nuclei were created using MRIcro software (University of Nottingham, Nottingham, UK). These subcortical structures were identified on a high-resolution structural template image within SPM99 (International Consortium for Brain Mapping 152 average), created from the average of 152 single subjects in the same stereotaxic space as the normalized EPIs. To determine executive differences between patient subgroups, activation effect size parameters were derived from the statistical model, using the mean of the data within the ROI contrast values. Values were derived in each patient for the comparisons of retrieval conditions versus motor control period and manipulation conditions versus motor control period. Because the simple and complex manipulation conditions produced nonsignificantly different results both behaviorally and in terms of imaging, they were collapsed into a single measure. All of these events required a single button press and thus had identical motor demands, therefore removing any confounding motoric differences that might have existed between patient subgroups. These values were then entered into an independent sample $t$ test within SPSS-PC, version 10.0 , to determine any significant differences between patient subgroups. For those ROI contrasts that showed significant activation differences between patient subgroups, a correlation analysis was performed in which the relationship between signal intensity and the reaction time constant for every subject was investigated using the bivariate correlation for Pearson's coefficient with a two-tailed test of significance. Subtracting the second response time from the first response time for the combined retrieval, simple manipulation, and complex manipulation conditions derived the reaction time constant for each subject, which was uncontaminated by motor-response latency.

\section{Results}

Clinical measures and performance parameters

No significant differences existed between age and sex in the three subject groups. The patient subgroups were well matched (Table
1) and showed no significant differences among their duration of disease, clinical severity and side of symptoms onset, motor phenotype, medications, or depression inventory scores. Furthermore, no significant differences among the patient subgroups were demonstrated on mini-mental state examination, verbal fluency, motor latency, and pattern and spatial recognition tasks.

Measurement of task accuracy on the working-memory paradigm showed that subjects performed more poorly as the conditions became more difficult $\left(F_{(2,28)}=9.97 ; p<0.001\right)$. However, there was no significant main effect of group $\left(F_{(2,28)}=1.39\right.$; $p=0.266)$ or interaction between group and task difficulty $\left(F_{(2,28)}=0.071 ; p=0.932\right)$. Similarly, reaction times for cognitive- and motor-response periods showed increases with task difficulty (cognitive response, $F_{(2,28)}=117.26, p<0.001$; motor period response, $\left.F_{(2,28)}=33.03, p<0.001\right)$ but no significant main effect of group (cognitive response, $F_{(2,28)}=2.5, p=$ 0.1 ; motor response, $\left.F_{(2,28)}=0.3, p=0.742\right)$ or interaction effect with group (cognitive response, $F_{(2,28)}=0.856, p=0.436$; motor period response, $\left.F_{(2,28)}=1.358, p=0.274\right)$.

\section{fMRI measurements}

The fMRI group analysis of all of the subjects, contrasting the retrieval and/or manipulation of information within working memory with the maintenance (retention) of the same information, revealed significant activation in the dorsolateral and ventrolateral prefrontal cortices, occipitoparietal junction, and the striatum, bilaterally (Table 2, Fig. 2).

The ROI analysis of the patient subgroups that contrasted separately retrieval and manipulation during the task with a motor control period showed significant bilateral underactivation of the caudate nuclei during retrieval in the patient subgroup with predefined executive impairment, compared with the patient subgroup with no cognitive impairment (left caudate, $t_{(19)}=2.1$, $p<0.05$; right caudate, $\left.t_{(19)}=2.1, p<0.05\right)$. During manipulation (Fig. 3), bilateral caudate underactivation was also observed (left caudate, $t_{(19)}=3.86, p<0.001$; right caudate, $t_{(19)}=3.9, p<$ 0.001 ), and in addition, the executively impaired patient subgroup exhibited significantly less activation in the dorsolateral (left, $t_{(19)}=2.1, p<0.05$; right, $t_{(19)}=2.35, p<0.05$ ) and ventrolateral prefrontal cortex (left, $t_{(19)}=2.1, p<0.05$; right, $\left.t_{(19)}=2.2, p<0.05\right)$ as well as the right putamen $\left(t_{(19)}=2.4 ; p<\right.$ $0.05)$, compared with the patients with no such deficit. This comparative underactivation was not global, because regions in oc- 
Table 2. Peak fMRI activity for working-memory paradigm

\begin{tabular}{|c|c|c|c|c|}
\hline \multirow[b]{2}{*}{ Region of interest } & \multirow{2}{*}{$\begin{array}{l}t \text { statistic } \\
(p<0.05)\end{array}$} & \multicolumn{3}{|c|}{ SPM99 stereotaxic coordinates } \\
\hline & & $x$ & $y$ & $z$ \\
\hline Right striatum & 6.4 & 18 & 4 & -2 \\
\hline Left striatum & 7.4 & -18 & 6 & -4 \\
\hline Right ventrolateral prefrontal cortex & 6.5 & 34 & 20 & -2 \\
\hline Left ventrolateral prefrontal cortex & 6.2 & -28 & 20 & 0 \\
\hline Right dorsolateral prefrontal cortex & 6.2 & 34 & 40 & 18 \\
\hline Left dorsolateral prefrontal cortex & 6.3 & -38 & 36 & 22 \\
\hline Right occipitoparietal junction & 8.8 & 32 & -74 & 24 \\
\hline Left occipitoparietal junction & 8.8 & -30 & -76 & 28 \\
\hline
\end{tabular}

Pattern of peak activations for the contrast combining all of the retrieval and manipulation conditions against the maintenance period for each subject in a random-effects model, corrected for multiple comparisons ( $p<0.05$ ).
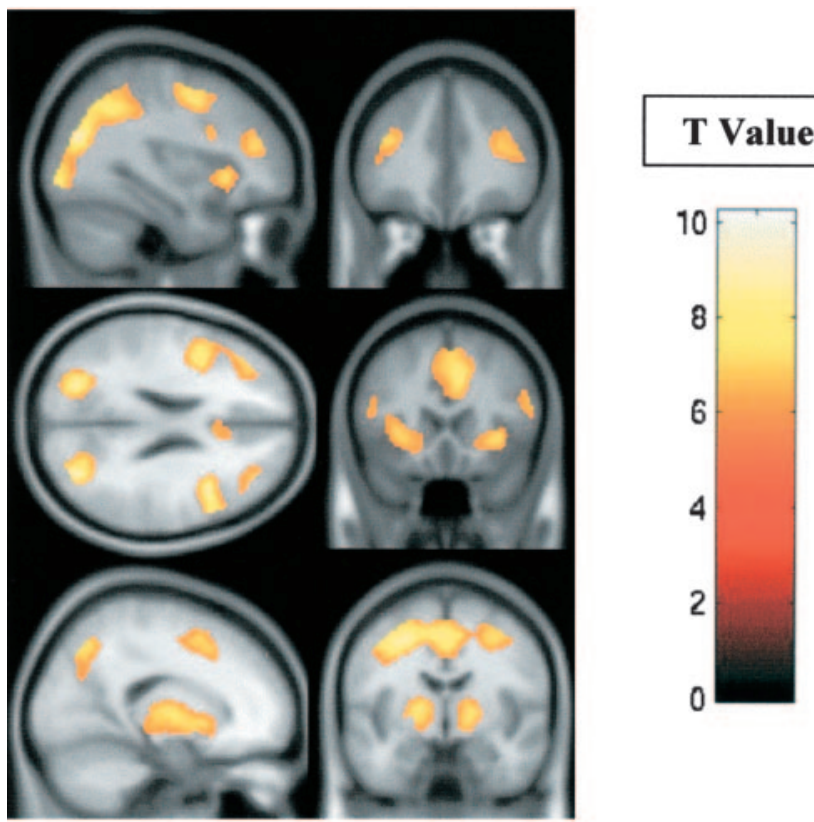

Figure 2. Pattern of fMRI activity during the working-memory paradigm. fMRI activity for the combined-subjects $(n=31)$ random-effects analysis using a one-sample $t$ test corrected for multiple comparisons at $p<0.05$, contrasting the period of the task spent retrieving and/or manipulating information within working memory with the period during which maintenance (retention) of the same information was required. Significant activity was observed in the dorsolateral and ventrolateral prefrontal cortices (top and middle panels), the striatum (bottom panels), and posterior association cortices, bilaterally (middle left panel). The color scale represents the T statistic.

cipitoparietal cortices that also responded during the workingmemory task showed no significant differences in activity when the patient subgroups were compared directly (left, $t_{(19)}=1.1$, $p=0.29$; right, $t_{(19)}=1.8, p=0.1$.

Finally, the correlation analysis comparing signal intensity changes with the reaction time constant for the task, performed on those ROIs that showed underactivity, revealed a significant negative correlation within the caudate nuclei for both retrieval and manipulation contrasts in the patient subgroup with predefined executive impairment $\left(r_{(9)}=-0.87, p<0.05 ; r_{(9)}=\right.$ $-0.72, p<0.05$, respectively), but in neither the controls (retrieval, $r_{(8)}=0.31, p=0.38$; manipulation, $r_{(8)}=0.28, p=0.43$ ) nor the subgroup of unimpaired patients (retrieval, $r_{(8)}=-0.22$, $p=0.54$; manipulation, $\left.r_{(8)}=-0.39, p=0.27\right)$. Similarly, significant negative correlations with executive impairment were observed during manipulation within the dorsolateral $\left(r_{(9)}=\right.$ $-0.83 ; p<0.05)$ and ventrolateral $\left(r_{(9)}=-0.82 ; p<0.05\right)$ prefrontal cortices as well as the putamen bilaterally $\left(r_{(9)}=\right.$ $-0.80 ; p<0.05)$ in this patient subgroup, but again not in the
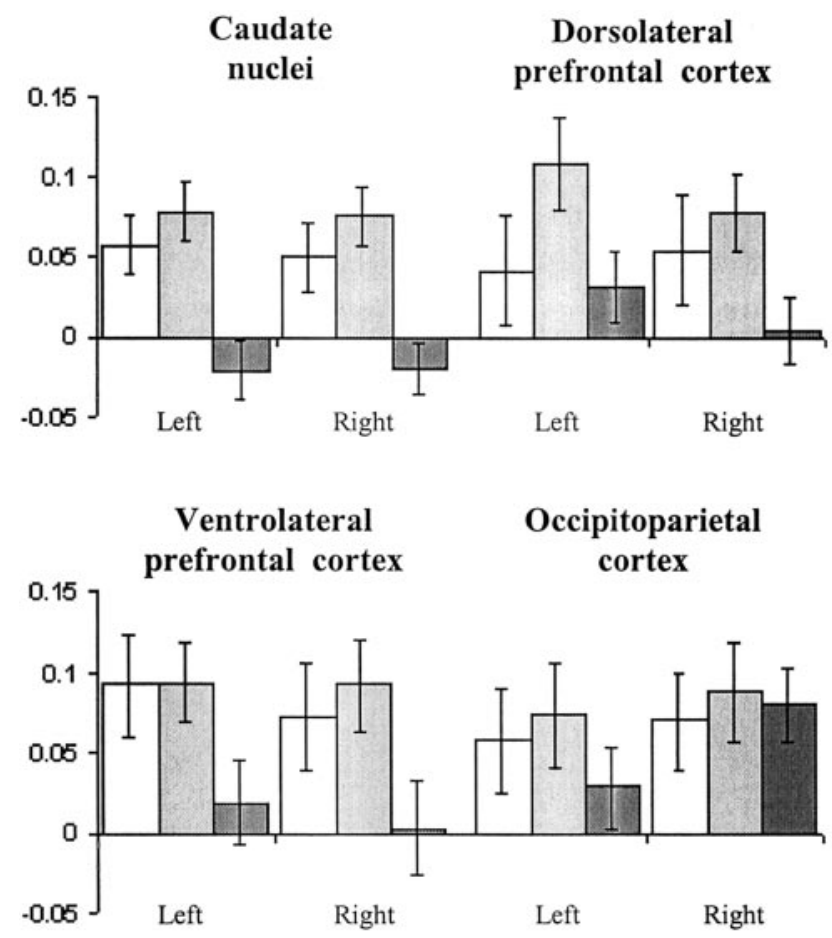

Figure 3. Regional mean $\mathrm{fMRI}$ signal during manipulation. The subgroup of patients with executive impairments $(\square)$ demonstrated significant underactivation $(p<0.05)$ compared with the unimpaired patients (圈) in the frontostriatal ROls, but not in the posterior association cortices. Control subjects ( $\square$ ) show activation that is broadly similar to the unimpaired patient subgroup. The mean fMRI signal (parameter estimates) reflects the mean of the ROI contrast values. Error bars represent SEM.

control group $\left(r_{(8)}=0.32, p=0.36 ; r_{(8)}=0.43, p=0.21 ; r_{(8)}=\right.$ $0.27, p=0.46$, respectively) or executively unimpaired patient $\operatorname{subgroup}\left(r_{(8)}=-0.36, p=0.34 ; r_{(8)}=-0.22, p=0.55 ; r_{(8)}=\right.$ $-0.15, p=0.67$, respectively). The occipitoparietal cortices showed no significant correlations for any of the subgroups (controls, $r_{(8)}=0.02, p \approx 1$; unimpaired patients, $r_{(8)}=-0.07, p \approx 1$; impaired patients, $\left.r_{(9)}=-0.01, p \approx 1\right)$.

\section{Discussion}

The results of the current study demonstrate, for the first time, that fMRI can be used to identify the neural locus of the selective executive deficit in a subgroup of patients with early PD. This impairment is related to specific underactivity in regions of the basal ganglia and frontal cortex, and preferentially affects processes involved in the manipulation of information within working memory. Although this effect was observed in an executively impaired subgroup of patients, signal intensity changes in a clinically matched executively unimpaired patient subgroup were 
broadly similar to that observed in healthy elderly controls (Fig. 3). The precise neural and neurochemical bases of signal intensity changes in the striatum and frontal lobes of patients with PD is not well understood: nondopaminergic forms of pathology, including noradrenergic, serotoninergic, and cholinergic deafferentation of the cortex (Agid et al., 1987), may play a significant role in some of the cognitive deficits observed in PD. Similarly, cortical Lewy bodies, which may occur even in the early stages, may play a contributory role (Byrne et al., 1989; Gibb et al., 1989). However, the fact that working-memory deficits have been shown previously to be extremely sensitive to the effects of controlled L-dopa withdrawal in groups of patients with PD (Lange et al., 1992) suggests a predominantly dopaminergic substrate for the deficits observed in the current study. Previous functional neuroimaging studies using fMRI and positron emission tomography (PET) have proposed conflicting neural mechanisms for cognitive impairment in PD with some results supporting a disturbance of the mesocortical projection (Cools et al., 2002; Mattay et al., 2002), whereas others identify a crucial role for disruption within the nigrostriatal circuitry (Owen et al., 1998a; Dagher et al., 2001).

Degeneration of the mesocortical dopamine system in PD is well recognized (Scatton et al., 1983) and may account, at least in part, for the reduced frontal lobe activity observed in the current study. It has been suggested that dopamine acting within the frontal cortex enables a focusing of activity of glutamatergic output neurons that, as a result, respond more efficiently (Mattay et al., 1996; Goldman-Rakic, 1998). However, the mesocortical projection is far less severely affected than the nigrostriatal dopamine system in PD (Agid et al., 1987), especially in the early stages of $\mathrm{PD}$, and depletion of striatal dopamine levels correlates with the severity of patients' motor symptoms (Morrish et al., 1996). Moreover, the imaging findings in this study demonstrate that a subgroup of PD patients with a selective executive deficit exhibit significant underactivation in the striatum as well as in the frontal cortex during performance of a working-memory task, compared to patients with no significant executive impairments. This underactivation in the executively impaired subgroup of PD patients was not a global effect, because there were no differences between patient subgroups in the posterior association cortices, which are also known to play a role in working memory (Owen et al., 1998b). As such, the current results suggest that some of the cognitive deficits in PD may reflect nigrostriatal dopaminergic depletion and its disruptive influence on the functioning of frontostriatal circuitry.

The main output of the dorsomedial projection of the nigrostriatal tract is to the head of the caudate nucleus (Bernheimer et al., 1973), and a correlation between the loss of dopaminergic neurons in this region and the degree of dementia observed during life in PD patients has been reported previously (Rinne et al., 1989). The fact that there was significant bilateral caudate underactivity in the executively impaired subgroup of patients compared with those patients with no impairment during both retrieval and manipulation concurs with these data, suggesting that these structures may play a more specific role in cognitive function than has been assumed previously. Animal lesion experiments also suggest that the caudate nuclei may play a specific role in cognition; for example, damage to different regions of the caudate nucleus produces deficits that resemble the effects of damage to their corresponding targets of projection within the prefrontal cortex (Divac et al., 1967). In addition, ${ }^{18} \mathrm{~F}$-dopa PET studies in PD patients have shown a correlation between dopaminergic depletion of the caudate nucleus and neuropsycholog- ical performance (Marie et al., 1999; Bruck et al., 2001), although these findings have not been universally reported (Broussolle et al., 1999; Rinne et al., 2000).

The selective underactivity of cortical structures during the manipulation, but not retrieval, of information within working memory in the patients with cognitive impairment suggests that executive deficits in PD are functionally specific and probably related to the organization of frontostriatal circuitry. The lateral frontal cortex has been implicated in higher order control functions (Petrides, 1994; D’Esposito et al., 1999; Owen, 2000), including manipulation in working memory, and it was only during that component of the task used in the current study that a relative inactivity in frontal ROIs was observed in the patients with executive impairment.

Previous neuropsychological studies of cognitive heterogeneity in PD have focused on the role of factors such as disease severity (Owen et al., 1992, 1993), medication (Lange et al., 1992; Owen et al., 1992), age (Aarsland et al., 1996), dominant motor symptom (Zetusky et al., 1985; Jankovic et al., 1990), and age of onset (Gibb and Lees, 1988b; Jankovic et al., 1990). However, the two patient groups in this study were well matched with respect to such clinical measures, and affective disorder had been excluded. Thus, the apparent difference between the two groups of patients is unlikely to reflect generalized differences in disease. Neither does the heterogeneity represent a global difference in cognitive capacity, because the patient subgroups could not be differentiated in terms of their performance on other cognitive tests with less executive loading (e.g., visual recognition memory). The results of this study therefore highlight the need for better characterization of patient groups and their impairments both neuropsychologically and motorically and may explain why previous studies in the area have sometimes produced apparently conflicting results (Owen et al., 1998a; Dagher et al., 2001; Cools et al., 2002; Mattay et al., 2002).

Current therapies in PD primarily target the motor symptoms of the disease, yet frank dementia is known to affect $15-20 \%$ of all sufferers (Brown and Marsden, 1984), and cognitive impairment is known to correlate with quality-of-life measures (Schrag et al., 2000). The results presented here clearly demonstrate that fMRI may have a potential future role in the assessment of $\mathrm{PD}$ patients by providing a means for identifying the neural substrate of selective cognitive impairment.

\section{References}

Aarsland D, Tandberg E, Larsen JP, Cummings JL (1996) Frequency of dementia in Parkinson disease. Arch Neurol 53:538-542.

Agid Y, Javoy-Agid E, Ruberg M (1987) Biochemistry of neurotransmitters in Parkinson's disease. In: Movement disorders (Marsden CD, Fahn S, eds), pp 166-230. London: Butterworth.

Beck AT, Ward CH, Mendelson M, Mock J, Erbaugh J (1961) An inventory for measuring depression. Arch Gen Psychiatry 4:561-571.

Benton AL (1983) Differential behavioural effects of frontal lobe disease. Neuropsychologia 6:53-60.

Bernheimer H, Birkmayer W, Hornykiewicz O, Jellinger K, Seitelberger F (1973) Brain dopamine and the syndromes of Parkinson and Huntington. Clinical, morphological and neurochemical correlations. J Neurol Sci 20:415-455.

Brett M, Leff AP, Rorden C, Ashburner J (2001) Spatial normalization of brain images with focal lesions using cost function masking. NeuroImage 14:486-500.

Broussolle E, Dentresangle C, Landais P, Garcia-Larrea L, Pollak P, Croisile B, Hibert O, Bonnefoi F, Galy G, Froment JC, Comar D (1999) The relation of putamen and caudate nucleus ${ }^{18} \mathrm{~F}$-dopa uptake to motor and cognitive performances in Parkinson's disease. J Neurol Sci 166:141-151.

Brown RG, Marsden CD (1984) How common is dementia in Parkinson's disease? Lancet 2:1262-1265. 
Bruck A, Portin R, Lindell A, Laihinen A, Bergman J, Haaparanta M, Solin O, Rinne JO (2001) Positron emission tomography shows that impaired frontal lobe functioning in Parkinson's disease is related to dopaminergic hypofunction in the caudate nucleus. Neurosci Lett 311:81-84.

Byrne EJ, Lennox G, Lowe J, Godwin-Austen RB (1989) Diffuse Lewy body disease: clinical features in 15 cases. J Neurol Neurosurg Psychiatry 52:709-717.

Cools R, Stefanova E, Barker RA, Robbins TW, Owen AM (2002) Dopaminergic modulation of high-level cognition in Parkinson's disease: the role of the prefrontal cortex revealed by PET. Brain 125:584-594.

Cusack R, Papadakis N (2002) New robust 3-d phase unwrapping algorithms: application to magnetic field mapping and undistorting echoplanar images. NeuroImage 16:754-764.

Dagher A, Owen AM, Boecker H, Brooks DJ (2001) The role of the striatum and hippocampus in planning: a PET activation study in Parkinson's disease. Brain 124:1020-1032.

D’Esposito M, Postle BR, Ballard D, Lease J (1999) Maintenance versus manipulation of information held in working memory: an event-related fMRI study. Brain Cogn 41:66-86.

Divac I, Rosvold HE, Szwarcbart MK (1967) Behavioral effects of selective ablation of the caudate nucleus. J Comp Physiol Psychol 63:184-190.

Fahn S, Elton R (1987) Unified Parkinson's Disease Rating Scale. In: Recent developments in Parkinson's disease (Fahn S, Marsden CD, Calne D, Goldstein M, eds), pp 153-163. Florham Park, NJ: Macmillan Health Care Information.

Folstein MF, Folstein SE, McHugh PR (1975) “Mini-mental state.” A practical method for grading the cognitive state of patients for the clinician. J Psychiatr Res 12:189-198.

Friston KJ, Holmes AP, Worsley KJ, Poline JB, Frith CD, Frackowiak RS (1995) Statistical parametric maps in functional imaging: a general linear approach. Hum Brain Mapp 2:189-210.

Friston KJ, Fletcher P, Josephs O, Holmes A, Rugg MD, Turner R (1998) Event-related fMRI: characterizing differential responses. NeuroImage 7:30-40.

Gibb WR, Lees AJ (1988a) The relevance of the Lewy body to the pathogenesis of idiopathic Parkinson's disease. J Neurol Neurosurg Psychiatry 51:745-752.

Gibb WR, Lees AJ (1988b) A comparison of clinical and pathological features of young- and old-onset Parkinson's disease. Neurology 38:1402-1406.

Gibb WR, Luthert PJ, Janota I, Lantos PL (1989) Cortical Lewy body dementia: clinical features and classification. J Neurol Neurosurg Psychiatry 52:185-192.

Goldman-Rakic PS (1998) The cortical dopamine system: role in memory and cognition. Adv Pharmacol 42:707-711.

Goodglass H (1972) Assessment of aphasia and related disorders. Philadelphia: Lea and Febiger.

Hoehn MM, Yahr MD (1967) Parkinsonism: onset, progression and mortality. Neurology 17:427-442.

Holmes AP, Josephs O, Buechel C, Friston KJ (1997) Statistical modelling of low frequency confounds in fMRI. NeuroImage 5:S480.

Jankovic J, McDermott M, Carter J, Gauthier S, Goetz C, Golbe L, Huber S, Koller W, Olanow C, Shoulson I (1990) Variable expression of Parkinson's disease: a base-line analysis of the DATATOP cohort. The Parkinson Study Group. Neurology 40:1529-1534.

Jellinger KA (2001) The pathology of Parkinson's disease. Adv Neurol 86:55-72.

Jezzard P, Balaban RS (1995) Correction for geometric distortion in echo planar images from B0 field variations. Magn Reson Med 34:65-73.

Karlsen KH, Larsen JP, Tandberg E, Maland JG (1998) Quality of life measurements in patients with Parkinson's disease: a community-based study. Eur J Neurol 5:443-450.

Lange KW, Robbins TW, Marsden CD, James M, Owen AM, Paul GM
(1992) L-Dopa withdrawal in Parkinson's disease selectively impairs cognitive performance in tests sensitive to frontal lobe dysfunction. Psychopharmacology (Berl) 107:394-404.

Lees AJ, Smith E (1983) Cognitive deficits in the early stages of Parkinson's disease. Brain 106:257-270.

Lewis SJ, Cools R, Robbins TW, Dove A, Barker RA, Owen AM (2003) Using executive heterogeneity to explore the nature of working memory deficits in Parkinson's disease. Neuropsychologia 41:645-654.

Marie RM, Barre L, Dupuy B, Viader F, Defer G, Baron JC (1999) Relationships between striatal dopamine denervation and frontal executive tests in Parkinson's disease. Neurosci Lett 260:77-80.

Mattay VS, Berman KF, Ostrem JL, Esposito G, Van Horn JD, Bigelow LB, Weinberger DR (1996) Dextroamphetamine enhances "neural network-specific" physiological signals: a positron-emission tomography rCBF study. J Neurosci 16:4816-4822.

Mattay VS, Tessitore A, Callicott JH, Bertolino A, Goldberg TE, Chase TN, Hyde TM, Weinberger DR (2002) Dopaminergic modulation of cortical function in patients with Parkinson's disease. Ann Neurol 51:156-164.

Morrish PK, Sawle GV, Brooks DJ (1996) Regional changes in $\left[{ }^{18} \mathrm{~F}\right]$ dopa metabolism in the striatum in Parkinson's disease. Brain 119:2097-2103.

Owen AM (2000) The role of the lateral frontal cortex in mnemonic processing: the contribution of functional neuroimaging. Exp Brain Res 133:33-43.

Owen AM, James M, Leigh PN, Summers BA, Marsden CD, Quinn NP, Lange KW, Robbins TW (1992) Fronto-striatal cognitive deficits at different stages of Parkinson's disease. Brain 115:1727-1751.

Owen AM, Beksinska M, James M, Leigh PN, Summers BA, Marsden CD, Quinn NP, Sahakian BJ, Robbins TW (1993) Visuospatial memory deficits at different stages of Parkinson's disease. Neuropsychologia 31:627-644.

Owen AM, Doyon J, Dagher A, Sadikot A, Evans AC (1998a) Abnormal basal ganglia outflow in Parkinson's disease identified with PET. Implications for higher cortical functions. Brain 121:949-965.

Owen AM, Stern CE, Look RB, Tracey I, Rosen BR, Petrides M (1998b) Functional organization of spatial and nonspatial working memory processing within the human lateral frontal cortex. Proc Natl Acad Sci USA 95:7721-7726.

Petrides M (1994) Frontal lobes and working memory: evidence from investigations of the effects of cortical lesions in non-human primates. In: Handbook of neuropsychology (Boller F, Grafman J, eds), pp 59-82. Amsterdam: Elsevier.

Rinne JO, Rummukainen J, Paljarvi L, Rinne UK (1989) Dementia in Parkinson's disease is related to neuronal loss in the medial substantia nigra. Ann Neurol 26:47-50.

Rinne JO, Portin R, Ruottinen H, Nurmi E, Bergman J, Haaparanta M, Solin O (2000) Cognitive impairment and the brain dopaminergic system in Parkinson disease: $\left[{ }^{18} \mathrm{~F}\right]$ fluorodopa positron emission tomographic study. Arch Neurol 57:470-475.

Scatton B, Javoy-Agid F, Rouquier L, Dubois B, Agid Y (1983) Reduction of cortical dopamine, noradrenaline, serotonin and their metabolites in Parkinson's disease. Brain Res 275:321-328.

Schrag A, Jahanshahi M, Quinn N (2000) What contributes to quality of life in patients with Parkinson's disease? J Neurol Neurosurg Psychiatry 69:308-312.

Taylor AE, Saint-Cyr JA, Lang AE (1986) Frontal lobe dysfunction in Parkinson's disease. The cortical focus of neostriatal outflow. Brain 109:845-883.

Worsley KJ, Marrett S, Neelin P, Vandal AC, Friston KJ, Evans AC (1996) A unified statistical approach for determining significant signals in images of cerebral activation. Hum Brain Mapp 4:58-73.

Zetusky WJ, Jankovic J, Pirozzolo FJ (1985) The heterogeneity of Parkinson's disease: clinical and prognostic implications. Neurology 35:522526 . 